\title{
A simple and inexpensive method of hydrogen isotope and water analyses of minerals and rocks based on zinc reagent
}

\author{
T.W. Vennemann and J.R. O'Neil \\ Department of Geological Sciences, University of Michigan, Ann Arbor, MI 48109, USA
}

(Received March 5, 1992; revised and accepted June 24, 1992)

\begin{abstract}
Vennemann, T.W. and O'Neil, J.R., 1993. A simple and inexpensive method of hydrogen isotope and water analyses of minerals and rocks based on zinc reagent. Chem. Geol. (Isot. Geosci. Sect. ), 103: 227-234.

A new method based on $\mathrm{Zn}$ reagent for the quantitative conversion $\mathrm{H}_{2} \mathrm{O}$ to $\mathrm{H}_{2}$ for the hydrogen isotope analysis of hydrous minerals and whole rocks has been developed. Analyses by this method are of comparable accuracy and precision $\left(\sim 1 \% ; \leqslant 0.1 \mathrm{wt} \%\right.$ error for determination of $\mathrm{H}_{2} \mathrm{O}$ ) to those of conventional extraction methods based on uranium reagent and is significantly simpler, faster and less expensive.
\end{abstract}

\section{Introduction}

Zinc has been used successfully as an alternative reductant to uranium for the quantitative conversion of $\mathrm{H}_{2} \mathrm{O}$ to $\mathrm{H}_{2}$ for $\mathrm{D} / \mathrm{H}$ determinations of water samples (e.g., Coleman et al., 1982; Kendall and Coplen, 1985) but not for hydrous minerals. In this paper we describe a new method for the hydrogen isotope and water analysis of hydrous minerals using $\mathrm{Zn}$ reagent. This method, which has been used successfully for the last two years at the University of Michigan, is largely a combination of the conventional technique using uranium reagent (e.g., Bigeleisen et al., 1952; Godfrey, 1962; Kyser and O'Neil, 1984) and those for water analyses based on $\mathrm{Zn}$ (e.g., Coleman et al., 1982). The technique described herein is an attractive alternative to the conventional reduction of $\mathrm{H}_{2} \mathrm{O}$ by uranium as it is fast, sim-

Correspondence to: T.W. Vennemann, Department of Geological Sciences, University of Michigan, Ann Arbor, MI 48109, USA. ple, relatively inexpensive and allows for precise and accurate analyses of small sample sizes. A large number of inquiries prompted us to publish the details of the technique.

The development of the method described below is an outgrowth of our detailed research performed to test the feasibility of a closed tube technique for the hydrogen isotope analysis of hydrous minerals as first suggested to us by $P$. Agrinier and M. Javoy (pers. commun., 1990). This closed tube technique involves quantitative reduction of the $\mathrm{H}_{2} \mathrm{O}$ in hydrous minerals or rocks by $\mathrm{Zn}$ reagent where sample and $\mathrm{Zn}$ are inserted into quartz tubes and, after evacuation, are heated to $1200^{\circ} \mathrm{C}$ in a resistance furnace. Unfortunately, rapid back-reaction between the $\mathrm{H}_{2}$ produced and the residual mineral/melt, in combination with hydrogen diffusion through the glass walls at these high temperatures results in inaccurate, variably shifted $\delta \mathrm{D}$-values for a range of minerals. Even though the measured values for a given mineral separate were very precise (better than $\pm 1 \% 0$ ), shifts in $\delta \mathrm{D}$ of up to $+20 \%$ from the 
true value appeared to be a critical function of the nature of the mineral (e.g., Fe content), necessitating variable correction factors and a detailed knowledge of the mineral chemistry prior to isotopic analysis.

\section{Description and results}

Since the technique currently used in the Stable Isotope Laboratory of the University of Michigan for the hydrogen isotope analysis of water forms the basis for our mass-spectrometer calibration and hence the basis for the mineral $\mathrm{D} / \mathrm{H}$ analyses, it is briefly described below. All values are reported in the familiar $\delta$ notation relative to SMOW (Vienna Standard Mean Ocean Water).

\section{1. $D / H$ analysis of water and volume calibration}

Microliter quantities of water of between $0.5-5 \mu \mathrm{l}(\sim 2 \mu \mathrm{l}$ is the routine amount) are injected by a gas-tight microsyringe into evacuated Pyrex ${ }^{\circledR}$ tubes ( $\sim 25 \mathrm{~cm}$ in length) containing $\mathrm{Zn}$ granules or shavings (Fig. 1). About $30-50 \mathrm{mg} \mathrm{Zn}$, or simply an excess amount, are used per expected $\mu \mathrm{l}$ of $\mathrm{H}_{2} \mathrm{O}$. Prior to use, the Pyrex ${ }^{\otimes}$ tubes are roasted at $500^{\circ} \mathrm{C}$ for a minimum of $1 \mathrm{hr}$ and then stored at $110^{\circ} \mathrm{C}$. For the analyses reported below, both $\mathrm{AnalaR}^{\circledR} \mathrm{Zn}$ shot $(0.5-2 \mathrm{~mm})$ and $\mathrm{Zn}$ laths supplied by the Biogeochemical Laboratory of the University of Indiana were used. No significant difference in results were observed between these two types of $\mathrm{Zn}$. Injection is made through a Silicone ${ }^{\circledR}$ septum held in place by a small neck in the glass. The water is transferred with gentle heating of the glass apparatus to the lower portion of the tube which is at liquid-nitrogen temperature. Any non-condensible gases are then pumped off and the tube is sealed off with a gas-oxygen flame. Sealed tubes containing water and $\mathrm{Zn}$ are then placed in a muffle furnace for $10 \mathrm{~min}$ at $480^{\circ} \mathrm{C}$. Under these conditions the reaction between $\mathrm{Zn}$ and $\mathrm{H}_{2} \mathrm{O}$ goes to

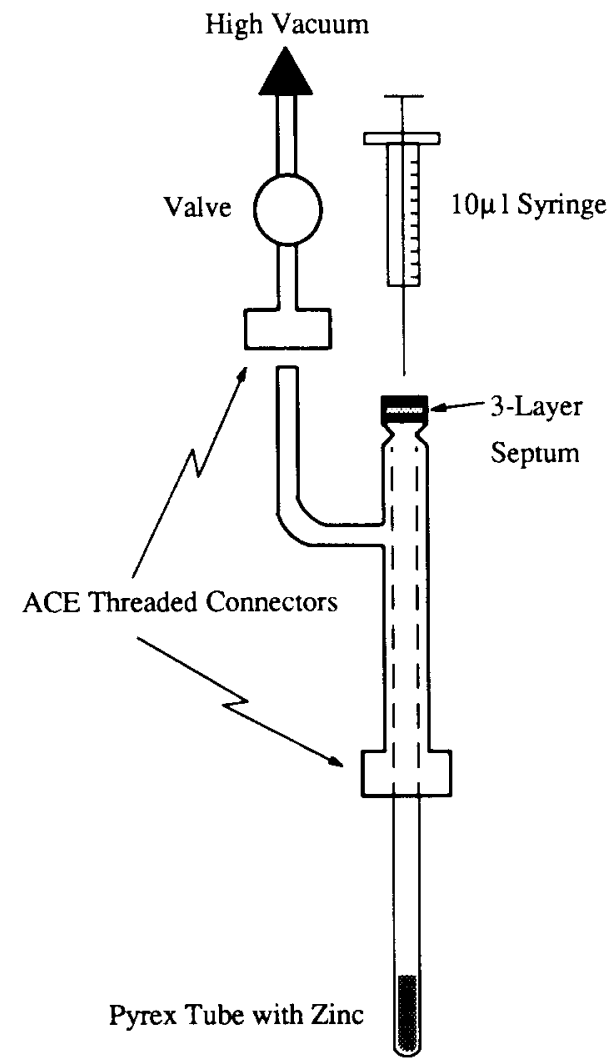

Fig. 1. Schematic representation of the apparatus used for the hydrogen isotope analysis of water samples.

completion, producing $\mathrm{ZnO}$ and a quantitative yield of $\mathrm{H}_{2}$. Subsequently the cooled tubes are cracked in vacuum on the mass spectrometer and the product $\mathrm{H}_{2}$ is analyzed for its hydrogen isotope composition. Results of some routine analyses of our in-house reference water and several standards are given in Table 1. The reference gas was calibrated using SMOW and SLAP (Standard Light Antarctic Precipitation), analyzed in the same fashion. We have stored reacted tubes at room temperature for up to 2 months without noticing any change in $\delta \mathrm{D}$-value of the contained gas. This technique can also be used for accurate $\mathrm{D} / \mathrm{H}$ measurements of brines but, unlike for samples of pure water, it requires occasional cleaning of the plugs and the interior walls of the glass apparatus to remove any residual salts. If the same syringe is used for a set of different 
TABLE 1

$\mathrm{D} / \mathrm{H}$ analyses of water

\begin{tabular}{|c|c|c|c|c|}
\hline \multirow[t]{2}{*}{ Sample } & \multicolumn{2}{|c|}{$\delta \mathrm{D}(\% 0$ vs. SMOW $)$} & \multirow[t]{2}{*}{$1 \sigma$} & \multirow[t]{2}{*}{$n$} \\
\hline & expected & measured & & \\
\hline $\begin{array}{l}\text { MDIW (in-house } \\
\text { standard) }\end{array}$ & -58 & -58 & 0.5 & 18 \\
\hline Inter-I & -96 & -96 & 0.8 & 2 \\
\hline Inter-2 & -127 & -128 & - & 1 \\
\hline Inter-4 & -85 & -86 & 0.5 & 2 \\
\hline Inter-5 (brine) & -80 & -81 & 0.7 & 2 \\
\hline Inter- 6 (brine) & -33 & -33 & 0.6 & 2 \\
\hline
\end{tabular}

$n=$ number of analyses.

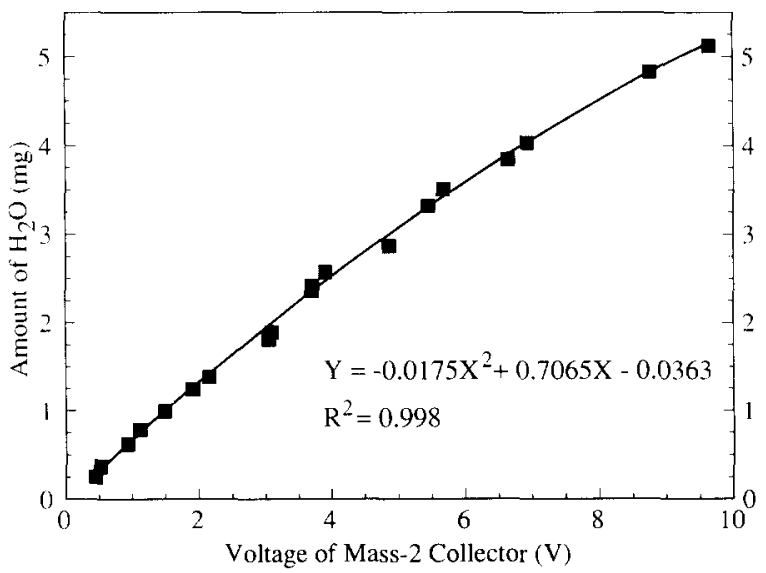

Fig. 2. Typical volume calibration curve of the inlet of the mass spectrometer (Finnigan ${ }^{\circledR}$ Mat-Delta $S$ ).

samples, it is advisable to purge the syringe with water from the next sample to be injected.

For the volume calibration of the inlet of our mass spectrometer (Finnigan ${ }^{\circledR}$ Mat-Delta S), weighed amounts of distilled water are reacted with $\mathrm{Zn}$ by the method just described and the $\mathrm{H}_{2}$ produced is expanded into a constant volume of the mass spectrometer sample inlet (Pyrex ${ }^{\circledR}$ tube length $=20 \pm 1 \mathrm{~cm}$ ). For a fixed volume, the voltage on the mass- 2 collector is proportional to the quantity of $\mathrm{H}_{2} \mathrm{O}$. This procedure is repeated for different amounts of water to establish a calibration curve (Fig. 2). The quantity of $\mathrm{H}_{2} \mathrm{O}$ from unknown samples is determined directly from the calibration curve with a precision of better than $\pm 0.1 \mathrm{wt} \%$.
The calibration curve is checked periodically to assure that source conditions of the mass spectrometer remain constant.

\subsection{Pyrex ${ }^{\circledR}$ vs. quartz or Vycor ${ }^{\circledR}$ tubing}

Experiments conducted to test for hydrogen isotope exchange between possible hydrogenbearing phases in the glass and hydrogen produced by the reduction of water within the glass tubes are summarized in Table 2. In agreement with the observations by Kendall and Coplen (1985), a change of $1-2 \%$ in the $\delta D$-values of hydrogen gas within Pyrex ${ }^{\circledR}$ tubes is noticeable for reaction times exceeding $1 \mathrm{hr}$. A similar change in $\delta \mathrm{D}$-value is also observed for very small samples $\left(<0.5 \mathrm{mg} \mathrm{H}_{2} \mathrm{O}\right)$ heated for 10 $20 \mathrm{~min}$ at $480^{\circ} \mathrm{C}$. For Pyrex ${ }^{\circledR}$ tubes containing $\mathrm{H}_{2}, \mathrm{Zn}$ and $\mathrm{ZnO}$ and held at $300^{\circ} \mathrm{C}$, a decrease in $\delta \mathrm{D}$ of up to $\sim 20 \%$ was observed after 65 $86 \mathrm{hr}$. However, no change in yield is observed, suggesting that no hydrogen has been lost by diffusion through the glass. In contrast to the behaviour in Pyrex ${ }^{\circledR}, \delta \mathrm{D}$-values of hydrogen in quartz and $\mathrm{Vycor}^{\circledR}$ tubes are not significantly changed after 1 hr at $480^{\circ} \mathrm{C}$ and only a small change $(\sim 2-4 \% 0)$ is observed for extended periods at $350^{\circ} \mathrm{C}$ (Table 2). However, significant loss of hydrogen by diffusion through quartz and $\mathrm{Vycor}^{\circledR}$ glass is indicated by low yields. It is possible that the small shift towards more positive $\delta \mathrm{D}$-values for hydrogen held in quartz and $\mathrm{Vycor}^{\circledR}$ tubes for extended periods at temperatures of $300^{\circ} \mathrm{C}$ is a result of the preferential diffusion of protium relative to deuterium. Furthermore, even for reaction periods of only $10 \mathrm{~min}$, there appears to be a $1-2 \%$ shift between $\delta \mathrm{D}$-values of hydrogen produced in Pyrex ${ }^{\circledast}$ relative to quartz and Vy$\operatorname{cor}^{(B)}$ tubes. It is likely that this difference may be a function of borosilicate glass containing significant amounts of hydrogen which is available for exchange with the hydrogen gas produced by reduction of $\mathrm{H}_{2} \mathrm{O}$ (Kendall and Coplen, 1985). Effects of this hydrogen isotope exchange can be minimized or effectively 
TABLE 2

$\mathrm{D} / \mathrm{H}$ exchange and diffusion of $\mathrm{H}_{2}$ in $\mathrm{Pyrex}^{\circledR}$, quartz and $\mathrm{Vycor}^{\circledR}$ tubes (all using MDIW $=-58 \%$ )

\begin{tabular}{lllll}
\hline Sample & $\begin{array}{l}\text { Amount of } \mathrm{H}_{2} \mathrm{O} \\
(\mathrm{mg})\end{array}$ & $\begin{array}{l}\text { Reaction time } \\
\left({ }^{\mathrm{h} \mathrm{m}}\right)\end{array}$ & $\begin{array}{l}\text { Temperature } \\
\left({ }^{\circ} \mathrm{C}\right)\end{array}$ & $\begin{array}{l}\delta \mathrm{D}(\%) \\
(\% \text { vs. SMOW })\end{array}$ \\
\hline
\end{tabular}

(A) Pyrex ${ }^{\circledast}$ tubes:

\begin{tabular}{|c|c|c|c|c|c|}
\hline$I$ & $\sim 2$ & $0: 30$ & 480 & -58 & - \\
\hline 2 & $\sim 2$ & $1: 00$ & 480 & -61 & - \\
\hline 3 & 1.63 & $24: 15$ & 300 & -73 & 99 \\
\hline 4 & $\sim 2$ & $40: 45$ & 300 & -74 & - \\
\hline 5 & 2.16 & $49: 00$ & 300 & -77 & 101 \\
\hline 6 & $\sim 2$ & $65: 50$ & 300 & -81 & - \\
\hline 7 & 2.27 & $86: 50$ & 300 & -75 & 101 \\
\hline \multicolumn{6}{|c|}{ (B) Quartz tubes: } \\
\hline$I$ & $\sim 2$ & $0: 30$ & 480 & -56 & - \\
\hline 2 & $\sim 2$ & $1: 00$ & 480 & -56 & - \\
\hline 3 & 2.26 & $26: 00$ & 350 & -54 & 95 \\
\hline 4 & 1.45 & $69: 00$ & 350 & -52 & 82 \\
\hline 5 & 2.19 & $86: 50$ & 300 & -46 & 94 \\
\hline \multicolumn{6}{|c|}{ (C) Vycor ${ }^{\otimes}$ tubes: } \\
\hline 1 & 2.81 & $0: 30$ & 480 & -57 & 99 \\
\hline 2 & 2.75 & $88: 50$ & 350 & -55 & 77 \\
\hline 3 & 2.80 & $133: 50$ & 350 & -52 & 65 \\
\hline
\end{tabular}

eliminated by using samples with $\gtrsim 1 \mathrm{mg} \mathrm{H}_{2} \mathrm{O}$, or alternatively using quartz or $\mathrm{Vycor}^{\circledR}$ tubes.

\section{3. $\mathrm{D} / \mathrm{H}$ analyses of minerals and whole rocks}

The extraction line used for the $\mathrm{D} / \mathrm{H}$ analysis of minerals is illustrated in Fig. 3. Weighed amounts of hydrous minerals are loaded into $\sim 12$-cm-long quartz tubes (6-mm o.d., 4-mm i.d.) which have been roasted at $800^{\circ} \mathrm{C}$ and stored at $110^{\circ} \mathrm{C}$ prior to use. A sufficient amount of mineral is loaded to obtain $\gtrsim 1 \mathrm{mg}$ $\mathrm{H}_{2} \mathrm{O}$. As a first approximation, the amount of water can be estimated from stoichiometry. We have run samples providing as little as $0.5 \mathrm{mg}$ $\mathrm{H}_{2} \mathrm{O}$ (e.g. $\sim 15 \mathrm{mg}$ of NBS- $30 @ 3.5 \mathrm{wt} \% \mathrm{H}_{2} \mathrm{O}$ ) and obtained accuracy and precision similar to those for larger samples (see Table 3 ). About $100-200 \mathrm{mg}$ of coarse-grained $(\sim 800 \mu \mathrm{m})$ quartz, which was previously decrepitated in a vacuum at $1100^{\circ} \mathrm{C}$, are then loaded above the sample followed by a small wad of quartz wool (pre-roasted at $800^{\circ} \mathrm{C}$ ). Addition of the quartz grains is a key aspect of the method. Most importantly it prevents collapse of the tube on heating, but also helps retain powders in the bottom of the tube during initial stages of degassing and can aid in lowering the temperature of water release by chemical reaction with the sample. In our system four samples thus loaded are attached to the extraction line via $\mathrm{ACE}^{\circledR, *}$ threaded glass connectors and evacuated simultaneously at $150^{\circ} \mathrm{C}$ by use of a predrilled aluminium heating block and a heating plate. At the same time, four Pyrex ${ }^{\circledR}$ tubes (20 $\mathrm{cm}$ long; 6-mm o.d.; 4-mm i.d.; pre-roasted at $500^{\circ} \mathrm{C}$ ) containing weighed amounts of $\mathrm{Zn}$ are also evacuated, as is the cupric oxide $(\mathrm{CuO}$ wire), which is packed into a quartz glass tube joined to the system via waxed ball and socket

*ACE Glass, Inc., Vineland, New Jersey, U.S.A. 


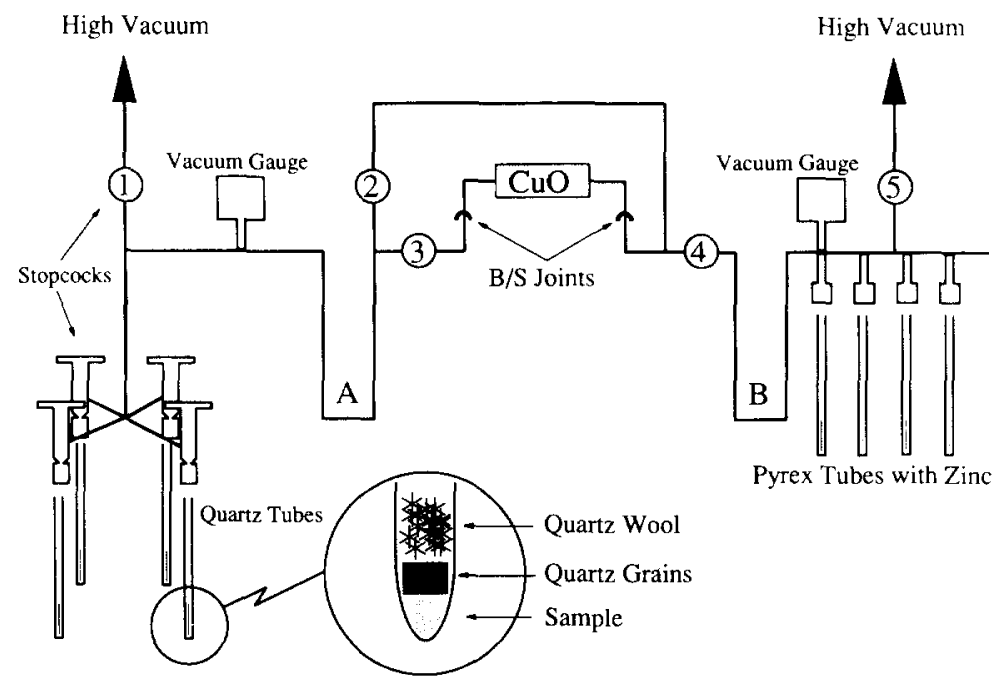

Fig. 3. Schematic representation of the vacuum extraction line used for the quantitative conversion of $\mathrm{H}_{2} \mathrm{O}$ to $\mathrm{H}_{2}$ for hydrogen isotope analysis of hydrous minerals and rocks. Overall horizontal distance is $\sim 80 \mathrm{~cm}$. All glass tubing consists of borosilicate glass (12-mm o.d.; traps $A$ and $B 10-\mathrm{mm}$ o.d.) except for the section containing the $\mathrm{CuO}$, which is made from 12 -mm (o.d.) quartz tubing. Stopcocks are high-vacuum O-ring types with a Teflon ${ }^{\circledR}$ plug (0-5-mm orifice; ACE Glass, Inc., Vineland, New Jersey, U.S.A.).

ground glass joints ( $18 / 9$ type). The $\mathrm{CuO}$ is held in place by quartz-wool plugs and heated to $700^{\circ} \mathrm{C}$ by a high-temperature heating tape. Once the samples are completely degassed (commonly $\sim 2 \mathrm{hr}$ in our system), all stopcocks to the sample tubes are closed except for that of the tube containing the sample to be extracted. The line is closed off from the pumping system (stopcocks 1 and 5), the bypass is isolated (stopcock 2) and liquid nitrogen is added to the bottom $1 / 3$ of traps $A$ and $B$. The sample contained in the quartz tube is then heated using a fuel-gas-oxygen torch (we have measured temperatures of $>1400^{\circ} \mathrm{C}$ inside the tube). To avoid heating the other samples and any background items, a graphite plate is held behind the sample tube during heating. Water released during heating is collected in $\operatorname{trap} A$ while hydrogen, which may be formed by reaction of released water with $\mathrm{Fe}$ in the sample, is oxidized by $\mathrm{CuO}$ held at $700^{\circ} \mathrm{C}$ and condensed in $\operatorname{trap} B$ as $\mathrm{H}_{2} \mathrm{O}$. Production of small amounts of hydrogen are particularly common for mafic samples (e.g., Kyser and O'Neil, 1984). Samples are heated until no further change in pressure is indicated by the vacuum gauge in front of trap $A$. Reaction times are commonly $\sim 3-4 \mathrm{~min}$, or $\sim 10 \mathrm{~min}$ in the case of large samples and/or whole rocks. While the quartz grains placed above the sample will prevent the quartz tube from collapsing, care must be taken to avoid heating above the quartz grains as the tube will readily collapse under vacuum.

Once the sample is completely dehydrated as evidenced by the reading on the vacuum gauge, traps $A$ and $B$ are topped-off and any non-condensible gases remaining are pumped out via stopcock 5. After evacuation of the non-condensible gases, stopcock 5 is closed, the stopcock to the first sample tube is closed and the liquid-nitrogen trap at $A$ is replaced by an acetone-dry ice (or similar temperature) slush trap and the non-condensibles are passed through the $\mathrm{CuO}$ and frozen at liquid-nitrogen temperatures in trap $B$. Thereafter, stopcock 3 is closed, 2 is opened and the slush removed. The released $\mathrm{H}_{2} \mathrm{O}$ is then transferred into trap $B$, bypassing the $\mathrm{CuO}$. During transfer the line is heated with a heat gun. The by-pass reduces 
TABLE 3

$\mathrm{D} / \mathrm{H}$ analyses of minerals

\begin{tabular}{|c|c|c|c|c|c|c|c|c|c|}
\hline \multirow[t]{3}{*}{ Mineral } & \multirow[t]{3}{*}{ Source* } & \multicolumn{2}{|l|}{ Expected } & \multicolumn{6}{|l|}{ Measured } \\
\hline & & \multirow{2}{*}{$\begin{array}{l}\delta \mathrm{D} \\
(\% 0 \mathrm{vs} . \\
\text { SMOW) }\end{array}$} & \multirow{2}{*}{$\begin{array}{l}\mathrm{H}_{2} \mathrm{O} \\
(\mathrm{wt} \%)\end{array}$} & \multicolumn{3}{|l|}{$\delta \mathrm{D}$} & \multicolumn{3}{|l|}{$\mathrm{H}_{2} \mathrm{O}$} \\
\hline & & & & $\begin{array}{l}\text { (\%ovs. } \\
\text { SMOW) }\end{array}$ & $1 \sigma$ & $n$ & $(w t \%)$ & $1 \sigma$ & $n$ \\
\hline $\begin{array}{l}\text { Biotite- } 1 \\
\text { (NBS-30) }\end{array}$ & & -65 & 3.50 & -64 & 1.4 & 10 & 3.49 & 0.06 & 10 \\
\hline Biotite-2 & {$[1]$} & -84 & 2.48 & -82 & 1.8 & 3 & 2.53 & 0.01 & 3 \\
\hline Biotite-3 & {$[2]$} & -62 & 3.53 & -60 & - & 1 & 3.62 & - & 1 \\
\hline Muscovite- 1 & [2] & -46 & $?$ & -46 & 1.2 & 4 & 4.24 & 0.08 & 4 \\
\hline Muscovite-2 & [3] & -64 & 2.70 & -57 & 0.6 & 2 & 3.32 & 0.04 & 2 \\
\hline Hornblende- 1 & {$[4]$} & -84 & 2.02 & -81 & 0.5 & 3 & 2.06 & 0.08 & 3 \\
\hline Hornblende-2 & {$[4]$} & -102 & 1.46 & -108 & 1.5 & 3 & 1.45 & 0.02 & 3 \\
\hline Hornblende- 3 & {$[4]$} & -62 & 1.86 & -55 & - & 1 & 1.77 & - & 1 \\
\hline Hornblende- 4 & [4] & -85 & 1.69 & -79 & _- & 1 & - & - & _- \\
\hline Chlorite & {$[3]$} & -83 & 10.10 & -66 & 0.7 & 3 & 11.20 & 0.02 & 3 \\
\hline Kaolinite/quartz & [5] & -46 & $?$ & -47 & 1.6 & 2 & 7.08 & 0.01 & 2 \\
\hline Kaolinite & [5] & -45 & $?$ & -42 & 0.8 & 2 & 13.38 & 0.15 & 2 \\
\hline Tourmaline & [3] & -36 & 2.40 & -58 & 2.0 & 2 & 2.92 & 0.06 & 2 \\
\hline Alunite-1 & {$[5]$} & -23 & $?$ & -21 & 1.0 & 2 & 13.21 & 0.50 & 2 \\
\hline Alunite-2 & [5] & -25 & $?$ & -25 & 2.0 & 2 & 11.90 & 0.01 & 2 \\
\hline
\end{tabular}

$n=$ number of samples; ? $=\mathrm{w} t \% \mathrm{H}_{2} \mathrm{O}$ unknown; $-=$ not determined.

*Sources: see text.

the time taken for the extraction, as passing $\mathrm{H}_{2} \mathrm{O}$ through the $\mathrm{CuO}$ heated to $700^{\circ} \mathrm{C}$ is relatively slow. For all of our work so far, no difference in yield nor $\delta \mathrm{D}$-value has been observed between $\mathrm{H}_{2} \mathrm{O}$ that is bypassed and $\mathrm{H}_{2} \mathrm{O}$ that is moved through the CuO. After complete transfer of $\mathrm{H}_{2} \mathrm{O}$ into trap $B(\sim 5 \mathrm{~min})$, stopcock 4 is closed, the Dewar containing liquid nitrogen is exchanged by one containing a dry ice-acetone slush and any non-condensible gases are pumped out via stopcock 5 (or may be collected, for example, $\mathrm{CO}_{2}$ released from crystallographic sites of the mineral). The $\mathrm{H}_{2} \mathrm{O}$ is subsequently transferred into a labelled Pyrex ${ }^{\circledR}$ tube containing $\mathbf{Z n}$.

The above procedure is then repeated for the other three samples. The extraction of four degassed samples takes $\sim 2-2.5 \mathrm{hr}$. Once sealed in the Pyrex ${ }^{\circledR}$ tubes containing $\mathrm{Zn}$, the tubes are inserted into a muffle furnace at $480^{\circ} \mathrm{C}$ for $10 \mathrm{~min}$ and are then ready for mass-spectro- metric analysis, including measurements of water contents as described above.

Typical results for a number of different minerals analyzed during the past year with this procedure are given in Table 3 . The reported $\delta \mathrm{D}$-values and water contents in Table 3 were obtained for different splits of the same mineral separates that were analyzed in other laboratories within the last few years by a conventional uranium procedure. These laboratories include the Stable Isotope Laboratories of the California Institute of Technology, United States Geological Survey (Menlo Park and Denver), University of Utah, and the University of Saskatoon. These laboratories are not identified in the table. In general, the method described here provides results for $\delta \mathrm{D}$ and water contents that are in good agreement with, and of comparable precision $( \pm 1-2 \% 0)$ to those obtained by the conventional uranium technique. Where differences exist, the sam- 
ples analyzed by our method, provide higher concentrations of $\mathrm{H}_{2} \mathrm{O}$ for all minerals analyzed (chlorite, muscovite and tourmaline). As most of these samples were analyzed in parallel with at least one NBS- 30 , whose $\delta \mathrm{D}$ and $w t \%$ $\mathrm{H}_{2} \mathrm{O}$ duplicated well, any significant differences in $\delta \mathrm{D}$ or $\mathrm{H}_{2} \mathrm{O}$ content are likely to be a function of incomplete $\mathrm{H}_{2} \mathrm{O}$ extraction in other laboratories or, alternatively, a function of different laboratory volume and $\delta \mathrm{D}$ calibrations.

\subsection{Special cases and some problems}

Over the last two years, the method described in this paper has been used successfully by a large number of researchers on a wide spectrum of minerals including muscovite, biotite, phlogopite, chlorite, epidote, tourmaline, hornblende, actinolite, pyrophyllite, kaolinite, montmorillonite, smectites, axinite, ilvaite $\left(\mathrm{CaFe}_{2+} 3 \mathrm{Fe}^{3+} \mathrm{O}\left(\mathrm{Si}_{2} \mathrm{O}_{7}\right)(\mathrm{OH})\right)$ and basaltic and granitic-granodioritic whole-rock samples. In only two cases, ilvaite and occasional mixed smectite-montmorillonite samples, the latter apparently containing minor $\mathrm{Fe}$ and Ti-oxides, did we encounter the problem of substantial reaction between the sample and the quartz tube, which can cause a break in the vacuum. In the case of ilvaite, a low-temperature (low oxygen) flame was found to release all the water and eliminate severe reaction with the quartz tube. In the case of the mixed smectite-montmorillonite samples $\sim 2 / 3$ sample were ground with $\sim 1 / 3$ quartz grains (degassed at $1100^{\circ} \mathrm{C}$ ) to provide excess reagent silica and then reacted in the normal way, producing results identical to those of similar samples not containing the Fe- and Ti-oxides. This procedure prevents the quartz tube from cracking.

For some whole rocks or mineral separates where large amounts of material are required $(\geqslant 70 \mathrm{mg}$ ), the partially melted quartz tube may develop fractures upon cooling. To avoid atmospheric contamination which may result from fracturing of the reagent tube, the stop- cock directly above the sample should be closed shortly after fusing the sample. As all $\mathrm{H}_{2} \mathrm{O}$ will have been removed from the small quartz tube, isolation of this part will not in any way affect the results.

Alunite, which produces significant quantities of acid (sulfurous?) upon rapid heating as a result of the simultaneous release of $\mathrm{H}_{2} \mathrm{O}$ and $\mathrm{SO}_{2}$, is also treated in a special way. This treatment is commonly off-line to the extraction system shown in Fig. 3 as $\mathrm{H}_{2} \mathrm{SO}_{4}$ is not volatile in a vacuum system and once added has to be washed out with water. Furthermore, the released acid also reacts with the FETFE $^{\circledR, *}$ O-rings used on the Teflon ${ }^{\circledR}$ stopcocks. Slow but gradual step-heating of alunite from $300^{\circ}$ to $650^{\circ} \mathrm{C}$ over a period of $\sim 1 \mathrm{hr}$, using a small resistance furnace, will maximize the release of $\mathrm{H}_{2} \mathrm{O}$ and minimize release of $\mathrm{SO}_{2}$. The water thus extracted is then distilled into Pyrex ${ }^{\circledR}$ tubes containing $\mathrm{Zn}$.

Fluid inclusion water can be extracted on the same system but the large amounts of material commonly required will necessitate the use of large quartz tubes $(\geqslant 10 \mathrm{~mm})$ and should be heated with resistance furnaces (maximum temperatures $\sim 1150^{\circ} \mathrm{C}$ ).

\section{Conclusions}

The method for the quantitative extraction and conversion of $\mathrm{H}_{2} \mathrm{O}$ from minerals using zinc reagent as described in this paper is an attractive alternative to the conventional techniques based on uranium (e.g., Bigeleisen et al., 1952 ). It provides comparable precision and accuracy relative to the conventional technique and is also relatively inexpensive and simple as it eliminates the need for an induction furnace, Toepler ${ }^{\circledR}$ pump, manometer, expensive metal foil and crucibles and complex cleaning procedures of the equipment involving dangerous acids. The technique described in this paper can be performed in almost any

\footnotetext{
*ACE Glass, Inc., Vineland, New Jersey, U.S.A.
} 
laboratory where a vacuum system, a torch and a muffle furnace are available. Furthermore, the hydrogen extracted from minerals and rocks can be stored for significant lengths of time and sent to other laboratories for massspectrometric analysis of the $\mathrm{H}_{2}$.

\section{Acknowledgements}

Financial support for this research was provided, in part, by a Foundation for Research Development (South Africa) post-doctoral bursary to T.W.V. and by National Science Foundation grant EAR-9005717 to J.R.O. We would like to thank M. Coleman, P. Fritz and Z. Sharp for their reviews.

\section{References}

Bigeleisen, J., Perlman, M.L. and Prosser, H.C., 1952. Conversion of hydrogenic materials to hydrogen for isotopic analysis. Anal. Chem., 24: 1356-1357.

Coleman, M.L., Shepherd, T.J., Durham, J.J., Rouse, J.E. and Moore, G.R., 1982. Reduction of water with zinc for hydrogen isotope analysis. Anal. Chem., 54: 993995.

Godfrey, J.D., 1962. The deuterium content of hydrous minerals. Geochim. Cosmochim. Acta, 26: 1214-1238.

Kendall, C. and Coplen, T.B., 1985. Multisample conversion of water to hydrogen by zinc for stable isotope determination. Anal. Chem., 57: 1437-1440.

Kyser, T.K. and O'Neil, J.R., 1984. Hydrogen isotope systematics of submarine basalts. Geochim. Cosmochim. Acta, 48: 2123-2133. 